\title{
Clinical Parameters Related to the Duration of Automatic Positive Airway Pressure Titration
}

\author{
Ji-Sun Kim, MD¹, Yun Jin Kang, MD², Chan-Soon Park, MD, PhD², Jae Hyung Hwang, MD², Yeon Ji Kim, MD² \\ 'Department of Otolaryngology-Head and Neck Surgery, Eunpyeong St. Mary's Hospital, College of Medicine, The Catholic University of Korea, Seoul, Korea \\ 2Department of Otolaryngology-Head and Neck Surgery, St. Vincent's Hospital, College of Medicine, The Catholic University of Korea, Suwon, Korea
}

\author{
Received: March 10, 2020 \\ Revised: May 19, 2020 \\ Accepted: June 2, 2020 \\ Correspondence \\ Chan-Soon Park, MD, PhD \\ Department of Otorhinolaryngology-Head \\ and Neck Surgery, \\ St. Vincent's Hospital, College of Medicine, \\ The Catholic University of Korea, \\ 93 Jungbu-daero, Paldal-gu, \\ Suwon 16247, Korea \\ Tel +82-31-249-8968 \\ Fax +82-31-257-3752 \\ E-mail pcs0112@catholic.ac.kr \\ ORCID \\ Ji-Sun Kim \\ https://orcid.org/0000-0003-4783-4654 \\ Yun Jin Kang \\ https://orcid.org/0000-0002-7677-4219 \\ Chan-Soon Park \\ https://orcid.org/0000-0003-3692-3344 \\ Jae Hyung Hwang \\ https://orcid.org/0000-0001-7249-0318 \\ Yeon Ji Kim \\ https://orcid.org/0000-0001-9908-8011
}

(c) This is an Open Access article distributed under the terms of the Creative Commons Attribution Non-Commercial License (https://creativecommons.org/licenses/by-nc/4.0) which permits unrestricted non-commercial use, distribution, and reproduction in any medium, provided the original work is properly cited.
Background and Objective Automatic positive airway pressure (APAP) therapy is a treatment and titration method for obstructive sleep apnea (OSA). However, little is known about the optimal duration of APAP titration for identifying effective pressure. 1) To evaluate the response of patients with OSA to low-span APAP titration for up to 3 months; 2) to find the optimal duration of APAP titration necessary to achieve the lowest treatment pressure; and 3) to identify variables that affect the APAP titration.

Methods This retrospective study was done in a single tertiary-care academic medical center. It included 50 patients with low-span APAP treatment from January 2016 to December 2018. The patients were divided into low-variation and high-variation groups depending on the median value (18\%) of change in the apnea-hypopnea index (AHI) from 1 week to 1 month.

Results The AHI estimated by the APAP machine showed different features over time in each group and changed significantly even after a month. The change in AHI was greater in patients with a larger forced vital capacity (FVC) (> 92.5\% predicted value) of a pulmonary function test, and was lesser in older (> 52 years) patients. This change was also compared with body composition between the two groups.

Conclusions Final titration pressure may be established at approximately 1 month after APAP titration. In particular, for patients with larger FVCs, it may be necessary to further adjust the treatment pressure to a minimum to improve compliance.

Sleep Med Res 2020;11(1):31-37

Key Words Sleep apnea, Obstructive, Sleep apnea syndromes, Forced vital capacity.

\section{INTRODUCTION}

Obstructive sleep apnea (OSA) is characterized by repeated episodes of partial or complete cessation of airflow during sleep. Because of its possible complications and long-term effects, the need to treat OSA is unquestionable. Although diverse treatment options have been suggested, positive airway pressure (PAP) therapy is generally accepted as the main treatments for OSA.

Continuous positive airway pressure (CPAP) was introduced as a therapy for OSA in 1981 [1]. Since then, it has been accepted as the first line of treatment for OSA in adults, particularly for those with moderate or severe OSA. Initially, commercially available equipment was used to deliver a fixed pressure based on a CPAP titration test in a sleep laboratory. However, a fixed pressure cannot instantly adapt to varying conditions of a patient during sleep, such as sleeping position, sedation, previous day-time activity, partial change in sleep time with sleep reduction, or nasal obstruction caused by various factors [2]. Conversely, automatic PAP (APAP) therapy can deliver different pressure levels to adapt to varying conditions during sleep using the algorithm developed by the device's manufacturer. Meta-analysis found that, although there was no difference in the therapeutic effects of CPAP and APAP on improving the apnea-hypopnea index (AHI), more patients preferred APAP over CPAP therapy [3]. 
The introduction of APAP equipment has been intended to provide a tool for avoiding the need to do additional in-lab titration. Recently, APAP devices have also been used for titration to find the best therapy pressure for OSA. However, there is no consensus on the optimal duration of APAP titration to establish treatment pressure. It is questionable whether consistent titration results could be obtained during short APAP titration windows. In actual practice, the duration of APAP titration might depend on a clinician's personal experience, and generally this duration is between one and two weeks. To the best of our knowledge, only one study has shown that one week is enough to find the optimal pressure of APAP at a high-span pressure setting [4]. Most APAP devices have a default setting of high-span pressure as 4 to $20 \mathrm{~cm} \mathrm{H}_{2} \mathrm{O}$ that is considered effective for most patients. However, one study found that patients were more compliant with low-span APAP treatments with a pressure range of 8 to $12 \mathrm{~cm} \mathrm{H}_{2} \mathrm{O}$ than with high-span APAP treatments with a pressure range of 4 to $15 \mathrm{~cm} \mathrm{H}_{2} \mathrm{O}$ [5].

In this study, we evaluated the response of patients with OSA to low-span APAP treatment that increased compliance for up to 3 months. Through this, we identified the optimal duration of APAP titration necessary to find the right treatment pressure. Also, we identified variables that affect APAP titration from findings of polysomnography (PSG), pulmonary function test (PFT), and body composition test.

\section{METHODS}

\section{Subjects and Basic Measurements}

From January 2016 to December 2018, we retrospectively reviewed the records of 58 OSA patients who were treated with low-span APAP, which was done for patients diagnosed with moderate to severe OSA (AHI > 15 events/h) based on the judgment of a sleep specialist. All patients underwent the Berlin Questionnaire, Epworth Sleepiness Scale, ENT examination, and fully attended overnight PSG. They were also tested by PFT and a body composition test using In-body ${ }^{\mathrm{TM}}$ (InBody Co., Ltd., Seoul, Korea) to identify obesity, abdominal obesity, and fat/muscle amount. We excluded those diagnosed with cognitive disability, congestive heart failure, and severe respiratory diseases. Patients with a central sleep apnea index greater than 10 events/h in baseline PSG and patients with AHI estimated by APAP machine (eAHI) greater than 10 events/h after APAP for a month were also excluded. Finally, a total of 50 OSA patients were included in this study. The protocol of this singlepatient group study with low-span APAP was approved by the Institutional Review Board, St. Vincent Hospital, the Catholic University of Korea, Suwon, ROK (VC19RESI0057).

\section{PSG}

The method of PSG was similar to those described in previ- ous reports except for scoring criteria for children [6,7]. The fully attended PSG was done with RemLogic-E ver.3.4.1 software (Embla Systems, Inc., Broomfield, CO, USA) and Embla N7000/S7000 hardware (Embla Systems, Inc.) at the sleep center at St. Vincent's Hospital. During the PSG test, 11 sensors were used to record various biological signals, as follows; 4 electroencephalography, 2 electrooculography, an electrocardiogram-lead, 3 electromyography at submentum and bilateral anterior tibialis muscles, and a body position sensor. To monitor respiratory events during sleep, a nasal pressure transducer, an oral thermistor, a thoracic and an abdominal respiratory plethysmography belts, a pulse oximeter, and a snoring sensor were used.

All PSG data were scored by a technician and then reviewed by a sleep specialist. Sleep stages, respiratory events, arousals, movements, and indexes of sleep-related events were scored according to the criteria of the American Academy of Sleep Medicine (AASM) scoring manual [8].

\section{Unattended APAP Titration and APAP Therapy}

All patients were fitted with masks and educated before using the APAP machine. The patients were administered APAP therapy using S10 ${ }^{\mathrm{TM}}$ Autocurve (ResMed Ltd., Bella Vista, Australia) or DreamStation (Philips Respironics, Bend, OR, USA). The setting of low-span APAP titration applied a pressure range of $4 \mathrm{~cm} \mathrm{H}_{2} \mathrm{O}$ within 6 to $12 \mathrm{~cm} \mathrm{H}_{2} \mathrm{O}$ in an unattended manner. The patients revisited the clinic one week, one month, and three months after the onset of APAP treatment. At each follow-up visit, the 90th or 95th percentile value of pressure (APAP ${ }^{9095}$ ) was recorded as a valid APAP titration pressure. In addition, OSArelated symptoms were re-evaluated by a sleep specialist in a standardized interview format, and mask-related discomfort was identified and resolved. Patients were encouraged to continue the APAP treatment, and all included patients met the conditions of APAP adherence for 3 months.

\section{Statistical Analyses}

Data are expressed as means \pm standard deviations or standard errors, including interquartile ranges for continuous variables and numbers or percentages for categorical variables. Baseline continuous variables were analyzed by an independent t-test or the Wilcoxon rank-sum test based on normality. Categorical variables were analyzed by a chi-square test or Fisher's exact test. Associations between eAHI variations and clinical outcomes were found by univariate and multivariate logistic regression analysis. All statistical analyses were done using SAS version 9.4 (SAS Institute, Cary, NC, USA). A p $<0.05$ was considered statistically significant.

\section{RESULTS}

All patients reached the therapeutic goal with an eAHI of less 
than 5 events/h within three months. One week after the application of APAP treatment, a maximum reduction in eAHI was observed compared to the baseline AHI established by diagnostic PSG (Fig. 1A). On the other hand, the change in eAHI between 1 week and 1 month after APAP was found to differ from patient to patient. Therefore, we divided them into two subgroups (low- and high-variation groups) based on the median value of change in eAHI (18\%) of all patients from 1 week to 1 month, with each subgroup containing 25 patients. Each group showed different features in eAHI changes by APAP treatment over time (Fig. 1B).

Except for the first week, there were significant differences in

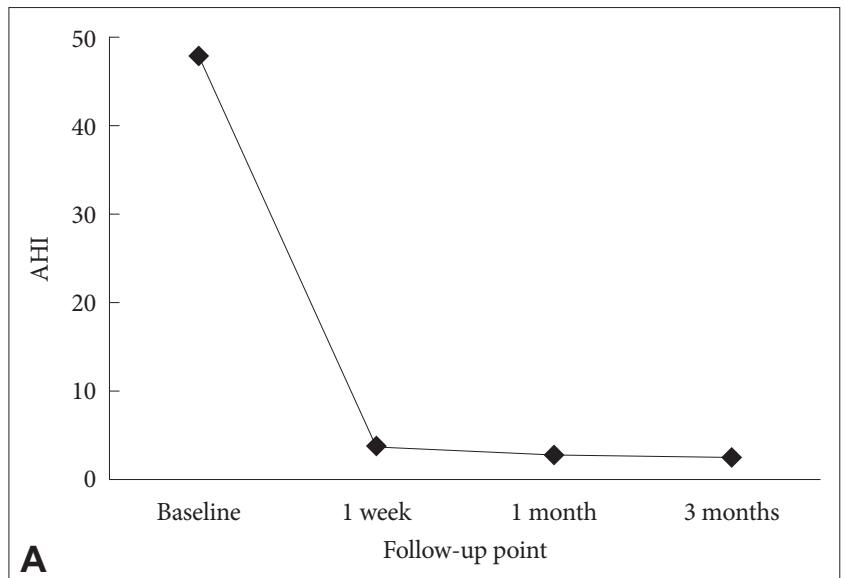

Fig. 1 Changes of AHI during APAP in patients with obstructive sleep apnea. A: Change of AHI in all patients from pretreatment to 3 months after APAP. B. Changes in AHI after 1 week, 1 month, and 3 months between the two groups divided in terms of the median value of all AHI changes (18\%) from 1 week to 1 month. All values except baseline are the AHI estimated by the APAP machine. AHI: apnea-hypopnea Index, APAP: automatic positive airway pressure.

Table 1. Characteristics of eAHI in two groups divided in terms of the eAHl change rate

\begin{tabular}{lccc}
\hline \multicolumn{4}{l}{ A. Comparison of eAHI between the two variation groups } \\
\hline & $\begin{array}{c}\text { Low variation } \\
\text { group }\end{array}$ & $\begin{array}{c}\text { High variation } \\
\text { group }\end{array}$ & p-value \\
\hline Baseline & $48.28 \pm 4.47$ & $50.30 \pm 3.84$ & 0.733 \\
1 week & $3.91 \pm 0.48$ & $3.84 \pm 0.46$ & 0.923 \\
1 month & $3.65 \pm 0.43$ & $2.21 \pm 0.37$ & $0.015^{*}$ \\
3 months & $3.34 \pm 0.43$ & $1.96 \pm 0.31$ & $0.012^{*}$
\end{tabular}

B. Comparison of eAHI differences between follow-up points in each variation group

\begin{tabular}{lcccc}
\hline & Low variation & & \multicolumn{2}{c}{ High variation } \\
& group & p-value & group & p-value \\
\hline 1 week-1 month & $0.26 \pm 0.10$ & $0.013^{*}$ & $1.64 \pm 0.38$ & $<0.001^{*}$ \\
1 week-3 month & $0.57 \pm 0.21$ & $0.014^{*}$ & $1.88 \pm 0.37$ & $<0.001^{*}$ \\
$1-3$ month & $0.30 \pm 0.18$ & 0.103 & $0.24 \pm 0.14$ & 0.093 \\
\hline
\end{tabular}

Data were analyzed by independent t-test and expressed as mean \pm standard error.

${ }^{*} \mathrm{p}<0.05$ was considered statistically significant.

eAHI: estimated apnea-hypopnea index by automatic positive airway pressure machine.
eAHI between the low- and high-variation groups at 1 month and 3 months after APAP treatment $(\mathrm{p}=0.015$ and $\mathrm{p}=0.012$, respectively) (Table $1 \mathrm{~A})$. The differences of $\mathrm{eAHI}$ in each variation group between 1 week and 1 month were $0.26 \pm 0.10$ and $1.64 \pm 0.38$, respectively, which were statistically significant $(\mathrm{p}=$ 0.013 and $\mathrm{p}<0.001$, respectively). However, differences of eAHI in each variation group between 1 month and 3 months were not significantly different $(\mathrm{p}=0.103$ and $\mathrm{p}=0.093$, respectively) (Table 1B). These results indicated that the changes in eAHI within each group occurred significantly after even one month.

The APAP ${ }^{9095}$ between the low- and high-variation groups at 1 week, 1 month, or 3 months were not significantly different

Table 2. Characteristics of APAP titration pressure in two groups divided in terms of eAHI change rate

\begin{tabular}{lccc}
\hline $\begin{array}{l}\text { A. Comparison of APAP titration pressure }\left(\mathrm{APAP}^{9095}\right) \\
\text { two variation groups }\end{array}$ & & \\
\hline & $\begin{array}{c}\text { Low variation } \\
\text { group }\end{array}$ & $\begin{array}{c}\text { High variation } \\
\text { group }\end{array}$ & p-value \\
\hline 1 week & $9.02 \pm 0.24$ & $9.50 \pm 0.34$ & 0.250 \\
1 month & $8.89 \pm 0.23$ & $9.49 \pm 0.27$ & 0.098 \\
3 month & $8.90 \pm 0.23$ & $9.46 \pm 0.25$ & 0.111 \\
\hline
\end{tabular}

B. Comparison of APAP ${ }^{9095}$ differences between follow-up points in each variation group

\begin{tabular}{lcccc}
\hline & $\begin{array}{c}\text { Low variation } \\
\text { group }\end{array}$ & p-value & \multicolumn{2}{c}{ High variation } \\
& group & p-value \\
\hline 1 week-1 month & $0.13 \pm 0.06$ & $0.028^{*}$ & $0.01 \pm 0.24$ & 0.960 \\
1 week-3 month & $0.11 \pm 0.09$ & 0.191 & $0.05 \pm 0.20$ & 0.812 \\
$1-3$ month & $-0.02 \pm 0.07$ & 0.814 & $0.04 \pm 0.09$ & 0.688 \\
\hline
\end{tabular}

Data were analyzed by independent t-test and expressed as mean \pm standard error.

${ }^{*}$ p-value $<0.05$ was considered statistically significant.

APAP: automatic positive airway pressure, eAHI: estimated apnea-hypopnea index by APAP machine, APAP ${ }^{9095}$ : 90th or 95th percentile pressure measured by APAP machine. 
(Table 2A). The differences in APAP ${ }^{9095}$ were not significant between the other follow-up points except between 1 week and 1 month in the low-variation group $(\mathrm{p}=0.028)$ (Table $2 \mathrm{~B})$.

Table 3 shows the results of the PSG, PFT, and body composition test of the two groups. There were statistically significant differences in age and body mass index (BMI) between the two groups ( $\mathrm{p}=0.010$ and $\mathrm{p}=0.026$, respectively). There were also significant differences in forced vital capacity (FVC) and forced expiratory volume in one second between the low- and highvariation groups $(\mathrm{p}=0.008$ and $\mathrm{p}=0.030$, respectively).
Univariate and multivariate logistic regression analyses were done to predict parameters for distinguishing the low- and highvariation groups (Table 4). On univariate analysis, an age over 52 years was associated with reduced odds of high variation [odds ratio (OR), 0.27; 95\% confidence interval (CI), 0.08-0.86; $\mathrm{p}=$ 0.026]. On the other hand, an FVC value above $92.5 \%$ of predictions was associated with increased odds of high variation (OR, 4.52; 95\% CI, 1.38-14.82; $\mathrm{p}=0.013$ ). These results were also significant in multivariate logistic analysis of age and FVC value. Polysomnographic findings or body composition param-

Table 3. Baseline characteristics in two groups divided in terms of estimated AHI by automatic positive airway pressure machine change rate

\begin{tabular}{|c|c|c|c|}
\hline & Low variation $(\mathrm{n}=25)$ & High variation $(\mathrm{n}=25)$ & p-value \\
\hline Age & $54.96 \pm 11.33$ & $47.12 \pm 9.32$ & $0.010^{\dagger}$ \\
\hline Sex, number of male (\%) & $23(92.0)$ & $21(84.0)$ & 0.667 \\
\hline Body mass index $\left(\mathrm{kg} / \mathrm{m}^{2}\right)$ & $28.16 \pm 4.42$ & $25.77 \pm 2.64$ & $0.026^{\dagger}$ \\
\hline \multicolumn{4}{|l|}{ Polysomnographic findings } \\
\hline AHI & $48.28 \pm 22.33$ & $50.30 \pm 19.22$ & 0.733 \\
\hline Apnea index* & $12.7(6.3-36.6)$ & $21.1(11.0-47.6)$ & 0.118 \\
\hline Hypopnea index & $27.74 \pm 11.19$ & $21.81 \pm 12.83$ & 0.088 \\
\hline RDI & $48.57 \pm 22.35$ & $50.58 \pm 18.98$ & 0.734 \\
\hline Oxygen desaturation index & $40.99 \pm 25.70$ & $43.34 \pm 21.98$ & 0.730 \\
\hline REM sleep of TST (\%) & $20.25 \pm 8.18$ & $18.12 \pm 5.11$ & 0.277 \\
\hline Respiratory arousal index* & $5.8(3.6-7.6)$ & $4.3(2.9-5.5)$ & 0.229 \\
\hline Supine RDI & $52.31 \pm 21.87$ & $48.70 \pm 16.31$ & 0.511 \\
\hline AHI in REM sleep & $45.18 \pm 16.77$ & $42.51 \pm 17.99$ & 0.591 \\
\hline Lowest oxygen saturation (\%) & $79.04 \pm 7.82$ & $78.48 \pm 9.58$ & 0.822 \\
\hline Saturation $<90 \%(\min )^{*}$ & $15.1(4.0-32.4)$ & $7.0(0.3-36.0)$ & 0.193 \\
\hline Apnea duration of TST (\%)* & $11.2(2.5-27.9)$ & $17.3(3.1-46.7)$ & 0.194 \\
\hline Hypopnea duration of TST (\%) & $19.09 \pm 7.86$ & $16.98 \pm 10.20$ & 0.417 \\
\hline \multicolumn{4}{|l|}{ Pulmonary function test } \\
\hline FVC (\% predicted value) & $90.92 \pm 9.21$ & $98.96 \pm 11.26$ & $0.008^{\dagger}$ \\
\hline FEV1 (\% predicted value) & $97.96 \pm 13.38$ & $106.28 \pm 12.97$ & $0.030^{\dagger}$ \\
\hline FEV1/FVC (\% predicted value) & $77.20 \pm 6.20$ & $78.84 \pm 4.98$ & 0.308 \\
\hline FEF25-75 (\% predicted value) & $91.20 \pm 30.37$ & $99.24 \pm 25.57$ & 0.316 \\
\hline \multicolumn{4}{|l|}{ Body composition } \\
\hline Body water $(\mathrm{L})$ & $41.57 \pm 5.35$ & $40.68 \pm 7.82$ & 0.640 \\
\hline Protein $(\mathrm{kg})$ & $11.14 \pm 1.47$ & $10.95 \pm 2.15$ & 0.720 \\
\hline Skeletal muscle (kg) & $32.00 \pm 6.00$ & $31.05 \pm 6.48$ & 0.591 \\
\hline Body fat (kg) & $24.37 \pm 9.54$ & $20.62 \pm 4.57$ & 0.085 \\
\hline Body fat rate $(\%)$ & $28.75 \pm 7.65$ & $27.37 \pm 5.53$ & 0.468 \\
\hline Abdominal fat rate $(\%)$ & $93.16 \pm 6.26$ & $91.44 \pm 3.43$ & 0.236 \\
\hline Visceral fat area $\left(\mathrm{cm}^{2}\right)$ & $111.41 \pm 44.39$ & $112.50 \pm 31.30$ & 0.921 \\
\hline
\end{tabular}

Analysis of sex was performed by chi-square test. Other variables were analyzed by independent t-test and expressed as mean \pm standard deviation.

*Analyses of the variables were performed by Wilcoxon rank sum test and expressed as median (interquartile ranges), ${ }^{\dagger} \mathrm{p}$-value $<0.05$ was considered statistically significant.

AHI: apnea-hypopnea index, RDI: respiratory disturbance index, TST: total sleep time, FVC: forced vital capacity, FEV1: forced expiratory volume in one second, FEF25-75: forced expiratory flow at $25-75 \%$ of the pulmonary volume. 
Table 4. Associations between estimated AHI by automatic positive airway pressure machine variations and baseline variables

\begin{tabular}{|c|c|c|c|c|}
\hline & \multicolumn{2}{|c|}{ Univariate } & \multicolumn{2}{|c|}{ Multivariate } \\
\hline & OR $(95 \% \mathrm{CI})$ & p-value & OR $(95 \% \mathrm{CI})$ & p-value \\
\hline Age $(>52)$ & $0.27(0.08-0.86)$ & $0.026^{*}$ & $0.16(0.04-0.67)$ & $0.012^{*}$ \\
\hline Sex (male) & $0.46(0.08-2.76)$ & 0.393 & & \\
\hline Body mass index $\left(>26 \mathrm{~kg} / \mathrm{m}^{2}\right)$ & $0.31(0.098-1.001)$ & 0.050 & & \\
\hline \multicolumn{5}{|l|}{ Polysomnographic findings } \\
\hline AHI $(>44.7)$ & $1.17(0.39-3.56)$ & 0.778 & & \\
\hline Apnea index (> 17.5) & $2.25(0.73-6.98)$ & 0.160 & & \\
\hline Hypopnea index (> 25.2) & $0.44(0.14-1.38)$ & 0.160 & & \\
\hline $\mathrm{RDI}(>46.1)$ & $1.17(0.39-3.56)$ & 0.778 & & \\
\hline Oxygen desaturation index $(>36.9)$ & $1.62(0.53-4.95)$ & 0.397 & & \\
\hline REM sleep of TST (> $18.8 \%$ ) & $0.52(0.17-1.61)$ & 0.257 & & \\
\hline Respiratory arousal index $(>4.8)$ & $0.44(0.14-1.38)$ & 0.159 & & \\
\hline Supine RDI (> 46.6) & $1.17(0.39-3.56)$ & 0.778 & & \\
\hline AHI in REM sleep (> 42.3) & $1.17(0.39-3.56)$ & 0.778 & & \\
\hline Lowest oxygen saturation (> $80 \%$ ) & $1.18(0.39-3.58)$ & 0.777 & & \\
\hline Saturation $<90 \%$ (> $11.6 \mathrm{~min})$ & $0.44(0.14-1.38)$ & 0.160 & & \\
\hline Apnea duration of TST (> $13.2 \%)$ & $1.62(0.53-4.95)$ & 0.397 & & \\
\hline Hypopnea duration of TST (> 17.6\%) & $0.62(0.20-1.89)$ & 0.397 & & \\
\hline \multicolumn{5}{|l|}{ Pulmonary function test } \\
\hline FVC (>92.5 \% predicted value) & $4.52(1.38-14.82)$ & $0.013^{*}$ & $7.19(1.72-30.01)$ & $0.007^{*}$ \\
\hline FEV1 (> $102 \%$ predicted value) & $3.19(0.999-10.17)$ & 0.050 & & \\
\hline FEV1/FVC (> $77.5 \%$ predicted value) & $1.17(0.39-3.56)$ & 0.778 & & \\
\hline FEF25-75 (\%) (> $97 \%$ predicted value) & $2.67(0.85-8.37)$ & 0.093 & & \\
\hline \multicolumn{5}{|l|}{ Body composition } \\
\hline Body water (> 40.5 L) & $0.52(0.17-1.61)$ & 0.260 & & \\
\hline Protein $(>10.1 \mathrm{~kg})$ & $1.88(0.52-6.85)$ & 0.337 & & \\
\hline Skeletal muscle $(>30.8 \mathrm{~kg})$ & $0.62(0.20-1.89)$ & 0.397 & & \\
\hline Body fat (> $20.1 \mathrm{~kg})$ & $0.44(0.14-1.38)$ & 0.160 & & \\
\hline Body fat rate (> $27.7 \%)$ & $0.44(0.14-1.38)$ & 0.160 & & \\
\hline Abdominal fat rate $(>0.92 \%)$ & $0.72(0.24-2.22)$ & 0.569 & & \\
\hline Visceral fat $\left(>111.5 \mathrm{~cm}^{2}\right)$ & $1.00(0.33-3.03)$ & $>0.999$ & & \\
\hline
\end{tabular}

All cut-off values were performed by median. Analyzed by univariate and multivariate logistic regression.

${ }^{*}$ p-value $<0.05$ was considered statistically significant.

RDI: respiratory disturbance index, TST: total sleep time, FVC: forced vital capacity, FEV1: forced expiratory volume in one second, FEF2575: forced expiratory flow at $25-75 \%$ of the pulmonary volume, AHI: apnea-hypopnea index, OR: odds ratio, CI: confidence interval.

eters did not show any significant OR.

\section{DISCUSSION}

CPAP therapy is indicated for treating moderate to severe OSA, for patients with mild OSA and associated symptoms, and/or for those with underlying cardiovascular disease $[9,10]$. Higher pressure is a very well-known requirement during REM sleep and when in supine position [2]. Therefore, CPAP titration must include a function to prevent airway occlusion during supine REM sleep, which might require pressure higher than what is necessary for the rest of the night [11]. The delivery of a constant high pressure during the entire night to cover respiratory problems during REM sleep might increase mask leaks, mouth leaks, and pressure intolerance that may reduce acceptance of and adherence to CPAP therapy. Additionally, the optimal pressure may change over time because of aging, sedation, alcohol consumption, weight gain or loss, or nasal congestion $[12,13]$.

With advances in technology and algorithms to surveil airflow during the night, auto-titrating devices for APAP therapy have 
been developed to respond to a patient's breathing pattern [14]. Theoretically, APAP therapy can outperform CPAP therapy by controlling patients' breathing during the night. However, effects of APAP therapy have been reported to be similar to those of CPAP therapy [15]. APAP users have demonstrated adherence similar to that of CPAP users and higher adherence than that of conventional CPAP users who are complaining of side effects [15-17]. Patient choice of either device can be affected by patient preference, specific reasons for nonadherence, cost, health-care service, and fixed-pressure requirements $[16,18]$. However, currently available APAP machines have several potential limitations. Most flow-based APAP machines have limited ability to distinguish between central and obstructive apnea or large mask leaks [19]. These flow patterns are interpreted by these devices as an absence of flow, which may lead to increases in pressure and worsening of central events or leaks in cases of central apnea. In addition, the ability of APAP devices to respond to sustained hypoventilation in the absence of upper-airway obstruction is currently unclear [20]. Because of these limitations, the AASM recommends that APAP devices should be used only for patients with uncomplicated moderate to severe OSA [12,21].

We did a preliminary study at Stanford Sleep Clinic to retrospectively examine 8 - to 14 -week outcomes in 10 patients diagnosed with OSA having an AHI oscillating between 10 and 48 events/h. These patients were treated using APAP with a pressure range of 5 to $20 \mathrm{~cm} \mathrm{H}_{2} \mathrm{O}$ as recommended by commercial entities. Of these patients, seven reported residual symptoms, primarily persistently waking up unrefreshed despite a full night's sleep. This preliminary study raised questions about the validity of commercial recommendations and whether APAP therapy could be actually more convenient for OSA patients than is CPAP therapy. Although initial setting of pressure between from 5 to $20 \mathrm{~cm} \mathrm{H}_{2} \mathrm{O}$ in APAP treatment has been widely used and accepted, clinical experience in our institution has shown that most OSA patients require less than $10 \mathrm{~cm} \mathrm{H}_{2} \mathrm{O}$ based on previous CPAP titration tests. Additional pressure from 10 to $20 \mathrm{~cm}$ $\mathrm{H}_{2} \mathrm{O}$ delivered by the algorithm of the APAP machine might be unnecessary or sometimes might make patients feel uncomfortable, with a negative impression of PAP. Thus, a low-span pressure setting may make patients feel more comfortable so that they can adjust easily to PAP and finally wear PAP more [5].

It should be noted that APAP has a double meaning of both treatment and titration modalities. Recently, APAP devices have been reported to be more useful for finding the optimal pressure for treating OSA than is an in-lab titration test [22]. The APAP titration has been suggested as an alternative to manual titration of PAP without valid long-term testing or confirmation of longterm outcomes $[23,24]$. It is as effective as manual titration to decrease AHI, improve subjective symptoms, and increase PAP adherence $[15,25,26]$. The APAP titration is also monitored for improvement of the patient's OSA with an APAP machine for a longer period than with in-lab titration. Therefore, it is advantageous as reflecting changes in daily sleep and OSA status and is a more comfortable titration method for patients [27]. One study has reported that one week of APAP titration seems sufficient to find an effective and stable PAP level [4]. In our study, most of the AHI changes occurred within 1 week, but eAHIs were stable at around one month after APAP treatment. Therefore, more time is needed than a week to confirm a stable eAHI and find the final APAP titration pressure.

The major limitation of PAP treatment has been with patients' adherence to it, which has been inconsistent and has increased only slightly since the introduction of CPAP in 1981 [28-30]. Several attempts have been made to increase adherence to PAP therapy, including group education and support, resolution of upper-airway problems, humidification, and behavioral intervention [9,31-34]. In general, the lower the PAP titration pressure, the higher the adherence, which was one reason that the lowest pressure was set to eliminate respiratory problems during CPAP titration. In this study, 19 out of 50 patients (38\%) showed an eAHI of less than 2 events/h at 1 month after APAP treatment, much lower than 5 events/h. The goal of PAP titration is to find the lowest pressure that makes AHI less than 5 in OSA. If the stable AHI is less than 5 by APAP treatment, even if the APAP pressure is readjusted lower to raise the AHI to 5 , the therapeutic goal may still be reached.

The first limitation of our study is that we used two APAP devices from different manufacturers. The patient's mask type, humidity, and pressure-relief functions of the devices were not the same. One sleep doctor judged the additional function of the devices with the same care pattern and provided one to each patient in the best condition. His intent was to increase the compliance with the use of PAP device, not to control these conditions for research purposes, because the goal of this study was to identify the tendency of eAHI changes after optimization of APAP for each patient. The second limitation is that our results were from retrospective studies derived from a small OSA patient sample. Therefore, a randomized controlled study with a larger sample size is required for clinical application. It is also clinically necessary to confirm the long-term results for more than 3 months.

In conclusion, The final decision on APAP titration pressure needed to prescribe CPAP pressure might be made at around 1 month, because eAHI might change on similar APAP ${ }^{9095}$ even after 1 month with low-span APAP treatment. Furthermore, patients with a large FVC are likely to have large eAHI variations.

\section{Acknowledgments}

The statistical consultation was supported by the Department of Biostatistics of the Catholic Research Coordinating Center.

\section{Conflicts of Interest}

The authors have no financial conflicts of interest. 


\section{Authors' Contribution}

Conceptualization: Park CS. Data curation: Kim JS, Park CS. Formal analysis: Kim JS, Park CS. Investigation: Kim JS, Kang YJ, Hwang JH, Kim YJ. Supervision: Park CS. Writing_original draft: Kim JS, Park CS, Hwang JH. Writing — review \& editing: Kim JS, Kang YJ, Park CS.

\section{REFERENCES}

1. Sullivan CE, Issa FG, Berthon-Jones M, Eves L. Reversal of obstructive sleep apnoea by continuous positive airway pressure applied through the nares. Lancet 1981;1:862-5.

2. Oksenberg A, Silverberg DS, Arons E, Radwan H. The sleep supine position has a major effect on optimal nasal continuous positive airway pressure: relationship with rapid eye movements and non-rapid eye movements sleep, body mass index, respiratory disturbance index, and age. Chest 1999;116:1000-6.

3. Xu T, Li T, Wei D, Feng Y, Xian L, Wu H, et al. Effect of automatic versus fixed continuous positive airway pressure for the treatment of obstructive sleep apnea: an up-to-date meta-analysis. Sleep Breath 2012; 16:1017-26.

4. Dias C, Sousa L, Batata L, Reis R, Teixeira F, Moita J, et al. Titration with automatic continuous positive airway pressure in obstructive sleep apnea. Rev Port Pneumol (2006) 2017;23:203-7.

5. Bastos HN, Cardoso AV, Castro AS, Gomes R, Pinto T, Marinho A, et al. Randomised short-term trial of high-span versus low-span APAP for treating sleep apnoea. Sleep Breath 2016;20:183-90.

6. Park CS, Guilleminault C, Park HJ, Cho JH, Lee HK, Son HL, et al. Correlation of salivary alpha amylase level and adenotonsillar hypertrophy with sleep disordered breathing in pediatric subjects. J Clin Sleep Med 2014;10:559-66.

7. Park CS, Guilleminault C, Hwang SH, Jeong JH, Park DS, Maeng JH. Correlation of salivary cortisol level with obstructive sleep apnea syndrome in pediatric subjects. Sleep Med 2013;14:978-84.

8. Berry RB, Budhiraja R, Gottlieb DJ, Gozal D, Iber C, Kapur VK, et al. Rules for scoring respiratory events in sleep: update of the 2007 AASM Manual for the Scoring of Sleep and Associated Events. Deliberations of the Sleep Apnea Definitions Task Force of the American Academy of Sleep Medicine. J Clin Sleep Med 2012;8:597-619.

9. Kushida CA, Littner MR, Hirshkowitz M, Morgenthaler TI, Alessi CA, Bailey D, et al. Practice parameters for the use of continuous and bilevel positive airway pressure devices to treat adult patients with sleeprelated breathing disorders. Sleep 2006;29:375-80.

10. Gay P, Weaver T, Loube D, Iber C; Positive Airway Pressure Task Force; Standards of Practice Committee, et al. Evaluation of positive airway pressure treatment for sleep related breathing disorders in adults. Sleep 2006;29:381-401.

11. Kushida CA, Chediak A, Berry RB, Brown LK, Gozal D, Iber C, et al. Clinical guidelines for the manual titration of positive airway pressure in patients with obstructive sleep apnea. J Clin Sleep Med 2008;4:157-71.

12. Littner M, Hirshkowitz M, Davila D, Anderson WM, Kushida CA, Woodson BT, et al. Practice parameters for the use of auto-titrating continuous positive airway pressure devices for titrating pressures and treating adult patients with obstructive sleep apnea syndrome. An American Academy of Sleep Medicine report. Sleep 2002;25:143-7.

13. Ashtyani H, Patel PB. CPAP or APAP--what is the real question? Respiration 2007;74:276-8.

14. Ryden A, Bando JM, Aysola RS. Auto-adjusting and advanced positive airway pressure therapeutic modalities. Semin Respir Crit Care Med 2014;35:593-603.

15. Fietze I, Glos M, Moebus I, Witt C, Penzel T, Baumann G. Automatic pressure titration with APAP is as effective as manual titration with CPAP in patients with obstructive sleep apnea. Respiration 2007;74:279-86.

16. Ip S, D’Ambrosio C, Patel K, Obadan N, Kitsios GD, Chung M, et al.
Auto-titrating versus fixed continuous positive airway pressure for the treatment of obstructive sleep apnea: a systematic review with metaanalyses. Syst Rev 2012;1:20.

17. Massie CA, McArdle N, Hart RW, Schmidt-Nowara WW, Lankford A, Hudgel DW, et al. Comparison between automatic and fixed positive airway pressure therapy in the home. Am J Respir Crit Care Med 2003; 167:20-3.

18. Nolan GM, Doherty LS, Mc Nicholas WT. Auto-adjusting versus fixed positive pressure therapy in mild to moderate obstructive sleep apnoea. Sleep 2007;30:189-94.

19. Rühle KH, Karweina D, Domanski U, Nilius G. [Characteristics of auto-CPAP devices during the simulation of sleep-related breathing flow patterns]. Pneumologie 2009;63:390-8.

20. Freedman N. Treatment of obstructive sleep apnea syndrome. Clin Chest Med 2010;31:187-201.

21. Berry RB, Parish JM, Hartse KM. The use of auto-titrating continuous positive airway pressure for treatment of adult obstructive sleep apnea. An American Academy of Sleep Medicine review. Sleep 2002;25:148-73.

22. Hertegonne K, Bauters F. The value of auto-adjustable CPAP devices in pressure titration and treatment of patients with obstructive sleep apnea syndrome. Sleep Med Rev 2010;14:115-9.

23. Lloberes P, Rodríguez B, Roca A, Sagales MT, de la Calzada MD, Giménez $\mathrm{S}$, et al. Comparison of conventional nighttime with automatic or manual daytime CPAP titration in unselected sleep apnea patients: study of the usefulness of daytime titration studies. Respir Med 2004; 98:619-25.

24. Hukins C. Comparative study of autotitrating and fixed-pressure CPAP in the home: a randomized, single-blind crossover trial. Sleep 2004;27: 1512-7.

25. Galetke W, Randerath WJ, Stieglitz S, Laumanns C, Anduleit N, Richter $\mathrm{K}$, et al. Comparison of manual titration and automatic titration based on forced oscillation technique, flow and snoring in obstructive sleep apnea. Sleep Med 2009;10:337-43.

26. Gao W, Jin Y, Wang Y, Sun M, Chen B, Zhou N, et al. Is automatic CPAP titration as effective as manual CPAP titration in OSAHS patients? A meta-analysis. Sleep Breath 2012;16:329-40.

27. Prasad B, Usmani S, Steffen AD, Van Dongen HP, Pack FM, Strakovsky I, et al. Short-term variability in apnea-hypopnea index during extended home portable monitoring. J Clin Sleep Med 2016;12:855-63.

28. van Zeller M, Severo M, Santos AC, Drummond M. 5-years APAP adherence in OSA patients--do first impressions matter? Respir Med 2013; 107:2046-52.

29. Richard W, Venker J, den Herder C, Kox D, van den Berg B, Laman M, et al. Acceptance and long-term compliance of nCPAP in obstructive sleep apnea. Eur Arch Otorhinolaryngol 2007;264:1081-6.

30. Weaver TE, Grunstein RR. Adherence to continuous positive airway pressure therapy: the challenge to effective treatment. Proc Am Thorac Soc 2008;5:173-8.

31. Pires FS, Drummond M, Marinho A, Sampaio R, Pinto T, Gonçalves $\mathrm{M}$, et al. Effectiveness of a group education session on adherence with APAP in obstructive sleep apnea--a randomized controlled study. Sleep Breath 2013;17:993-1001.

32. Park P, Kim J, Song YJ, Lim JH, Cho SW, Won TB, et al. Influencing factors on CPAP adherence and anatomic characteristics of upper airway in OSA subjects. Medicine (Baltimore) 2017;96:e8818.

33. Richards D, Bartlett DJ, Wong K, Malouff J, Grunstein RR. Increased adherence to CPAP with a group cognitive behavioral treatment intervention: a randomized trial. Sleep 2007;30:635-40.

34. Smith I, Nadig V, Lasserson TJ. Educational, supportive and behavioural interventions to improve usage of continuous positive airway pressure machines for adults with obstructive sleep apnoea. Cochrane Database Syst Rev 2009;(2):CD007736. 